\title{
Total Body Calcium by Whole Body Neutron Activation: New Technique for Study of Bone Disease
}

\author{
M. J. CHAMBERLAIN,* M.B., M.R.C.P. ; J. H. FREMLIN, $\dagger$ M.A., D.SC., PH.D. \\ D. K. PETERS, $\ddagger$ M.B., M.R.C.P. ; HELEN PHILIP,§ PH.D.
}

\section{Erit. med. F., 1968, 2, 581- 83}

The fundamental pathological processes of diseases involving generalized disturbance of skeletal mineralization are ill understood, and treatment is often unsatisfactory. Radiographic techniques are widely used in the diagnosis and management of bone disease. Such techniques are fundamentally dependent on the radio-opacity of skeletal calcium. The most careful radiological assessments may not detect skeletal demineralization until as much as $40 \%$ of skeletal calcium is lost (Simon, 1965).

Anderson et al. (1964) showed that the technique of neutron activation analysis could be applied to the measurement of total body sodium and chlorine in the living subject. These workers also pointed out that total body calcium might be measured in this way. First considerations suggest that calcium is an unsuitable element for detection by neutron activation, since the only suitable isotope produced is ${ }^{49} \mathrm{Ca}$ with a half-life of 8.9 minutes, produced from ${ }^{48} \mathrm{Ca}$, which forms only $0.18 \%$ of the element and which is not a strong absorber of neutrons. ${ }^{49} \mathrm{Ca}$, however, produces a gamma ray of high energy $(3.05 \mathrm{MeV})$. This is readily detected by the whole body counter, and with appropriate pulse height analysis is easily separated from much larger activities of lower energy radiation. We have carried out neutron activation analysis on three cadavers and three living subjects. A system of activation and counting has been established which provides a measure of total body calcium. The accuracy of measurement represents a substantial improvement on currently used investigative techniques.

\section{Experiments}

Though calcium is activated exclusively by slow (lowenergy) neutrons a human subject cannot be irradiated directly by these since most would be absorbed by a few centimetres of flesh. Highly penetrating fast neutrons must be used, the body itself moderating them. The Birmingham 60-in. (152$\mathrm{cm}$.) cyclotron was used as a neutron source. The neutrons were produced by bombarding a natural lithium target with protons. This resulted in a fast neutron flux of approximately $3 \times 10^{5}$ neutron $/ \mathrm{sq}$. $\mathrm{cm}$./ $/ \mathrm{sec}$. at $2 \mathrm{~m}$. with a mean energy of approximately $3 \mathrm{MeV}$ (range 0.1 to $8.0 \mathrm{MeV}$ ). A series of experiments were carried out using a crude polyethylene phantom consisting of a stack of polyethylene plates, and polyethylene bottles containing calcium phosphate. The slow neutron flux at different depths in the stack was measured by the activity in foils of indium (which is also activated by slow neutrons). These experiments established: (1) that uniformity of irradiation of the skeleton would be expected if the subject were irradiated from two opposite directions, provided

\footnotetext{
* Lecturer in Experimental Pathology, University of Birmingham. † Professor of Applied Radioactivity, University of Birmingham.

‡ Honorary Research Fellow in Experimental Pathology, University of Birmingham. Present address: Division of Biophysics, Nationl Institute of Medical Research, London S.W.7.

$\$$ Research Associate in Medical Biochemistry, University of Birmingham.
}

that a suitable layer of hydrogenous material surrounded the skeleton to provide partial moderation of fast neutrons; and (2) that adequate counting rates of ${ }^{49} \mathrm{Ca}$ should be obtained with radiation doses of approximately 1 rem. It proved possible to achieve uniformity of neutron flux over a field large enough to accommodate a human subject at $2 \mathrm{~m}$. from the source. Details of the experiments and the reason for using neutrons of this energy are given by Chamberlain et al. (1968a, 1968b).

On the basis of these preliminary experiments neutron activation was carried out on cadavers. A total of seven activations were performed on three cadavers. A wooden coffin $(1.5 \mathrm{~cm}$. thick) conveniently provided the necessary moderation of fast neutrons. Uniformity of activation was achieved by irradiating first posteroanteriorly and then from the opposite direction. The irradiation times were arranged to compensate for the decay of ${ }^{49} \mathrm{Ca}$ during the first half of activation; the total irradiation time was 5 minutes 16 seconds. The slow neutron flux was measured by the activity produced in indium foils, suitably placed in the neutron field. After activation the cadaver was quickly transferred to the whoie body counter. The whole body counter is based on four 12.1 by $10.5 \mathrm{~cm}$. sodium iodide crystals, completely shielded by $15 \mathrm{~cm}$. of armour-plate steel lined by $3 \mathrm{~mm}$. of lead. The spectrum is analysed by a 512-channel pulse-height analyser, and processed by a programme using the KDF9 computer of the University of Birmingham. The ${ }^{49} \mathrm{Ca}$ activity $(3.05 \mathrm{MeV})$ is based on the $2.92-3.30 \mathrm{MeV}$ range. Repeated counting showed that the activity in this range had a half-life closely corresponding with ${ }^{49} \mathrm{Ca}$ (8.9 minutes). The results of seven activations in three cadavers are shown in Table I. Included

TABLE I.-Results of Activation Analysis in Three Cadavers

\begin{tabular}{|c|c|c|c|c|c|}
\hline $\begin{array}{c}\text { Activa- } \\
\text { tion }\end{array}$ & Cadaver & $\begin{array}{l}{ }^{116} \text { Indium } \\
\text { (c. } / 60 \mathrm{sec} .)\end{array}$ & $\begin{array}{c}{ }^{49} \mathrm{Calcium} \\
(\mathrm{c} . / 1,024 \text { sec. }\end{array}$ & ${ }^{49} \mathrm{Ca} /{ }^{116} \mathrm{In}$ & ${ }^{49} \mathrm{Ca} /{ }^{24} \mathrm{Na}$ \\
\hline $\begin{array}{l}1 \\
2 \\
3 \\
\end{array}$ & $\begin{array}{l}\text { A } \\
\text { A } \\
\text { A }\end{array}$ & $\begin{array}{l}3,080 \\
2,700 \\
3,180 \\
\end{array}$ & $\begin{array}{l}7,750 \\
8,430 \\
8,700 \\
\end{array}$ & $\begin{array}{l}2.515^{*} \\
3.110 \\
2.730 \\
\end{array}$ & $\begin{array}{l}0.931 \\
0.975 \\
0.937 \\
\end{array}$ \\
\hline $\begin{array}{l}4 \\
5 \\
\end{array}$ & $\begin{array}{l}\mathbf{B} \\
\mathbf{B} \\
\end{array}$ & $\begin{array}{l}2,750 \\
3,410 \\
\end{array}$ & $\begin{array}{l}8,710 \\
8,672 \\
\end{array}$ & $\begin{array}{l}3.055 \\
2.543^{*}\end{array}$ & $\begin{array}{l}1.300 \\
1.340\end{array}$ \\
\hline $\begin{array}{l}6 \\
7\end{array}$ & C & $\begin{array}{l}3,100 \\
2,700\end{array}$ & $\begin{array}{l}9,140 \\
7,700\end{array}$ & $\begin{array}{l}2.955 \\
2.855\end{array}$ & $\begin{array}{l}1.045 \\
1.286\end{array}$ \\
\hline
\end{tabular}

is the ${ }^{24} \mathrm{Na}(2.76 \mathrm{MeV})$ activity, produced by activation of the stable element ${ }^{23} \mathrm{Na}$. We were encouraged by the reproducibility of the ${ }^{49} \mathrm{Ca} /{ }^{24} \mathrm{Na}$ ratios, the ${ }^{24} \mathrm{Na}$ activity acting for this purpose as an internal standard. Activations one and five were carried out from one direction only. This accounts for much of the variation in counting rates in the same subject.

In order to obtain information about the reproducibility of the system it was decided to activate repeatedly a cadaver under constant conditions of neutron bombardment. The result of eight successive activations is shown in Table II. The ${ }^{49} \mathrm{Ca}$ values have a standard deviation of $\pm 3.7 \%$. Statistical errors of counting are responsible for some of this. These experi- 
ments showed that total body calcium could be measured in cadavers by using small radiation doses and that the results were reproducible. It was decided, therefore, to proceed to studies on the living subject. The conditions were the same as those used in the cadaver experiments. A wooden coffin was used to provide moderation of fast neutrons. Three subjects (J. H. F., M. J. C., and D. K. P.) were studied. For the measurement of ${ }^{49} \mathrm{Ca}$ two counts were made, at 7 and 14 minutes after activation. The initial activity was found by extrapolation to zero time. The results are shown in Table III.

TABle II.- $-{ }^{4} \mathrm{Ca}$ Activities Produced by Eight Successive Activations of the Same Cadaver Under Constant Conditions of Neutron Bombardment
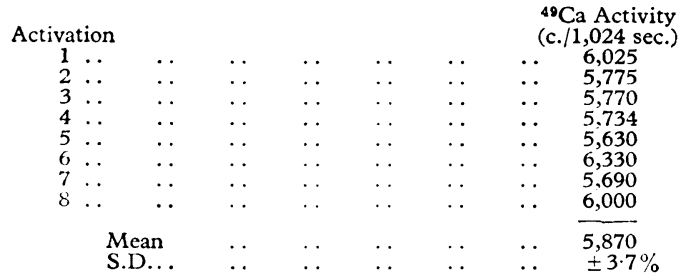

TABLE III.-Results of Neutron Activation in Three Living Subjects

\begin{tabular}{|c|c|c|c|}
\hline Subject: & J.H.F. & M.J.C. & D.K.P. \\
\hline 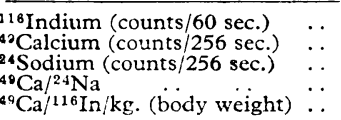 & $\begin{array}{c}1,206 \\
2,630 \\
1,870 \\
1 \cdot 406 \\
2 \cdot 87 \times 10^{-2}\end{array}$ & $\begin{array}{c}1,113 \\
2,895 \\
1,677 \\
1.726 \\
3.07 \times 10^{-2}\end{array}$ & $\begin{array}{c}1,099 \\
2,540 \\
1,570 \\
1 \cdot 618 \\
3 \cdot 10 \times 10^{-2}\end{array}$ \\
\hline
\end{tabular}

Subjects D. K. P. and M. J. C. show very close agreement for ${ }^{49} \mathrm{Ca}$ when corrected for the different neutron doses (based on ${ }^{116} \mathrm{In}$ activities) and standardized for body weight. The ${ }^{49} \mathrm{Ca} /{ }^{16} \mathrm{In} / \mathrm{Kg}$. values are respectively $3.10 \times 10^{-2}$ and $3.07 \times$ $10^{-2}$. The value in J.H. F. is slightly lower, $2.87 \times 10^{-2}$. This is also reflected in the ${ }^{49} \mathrm{Ca} /{ }^{24} \mathrm{Na}$ ratios, which are 1.618 and 1.726 for D. K.P. and M.J.C. but 1.406 for J.H.F. These results may well reflect the difference in age between D. K. P. (29), M. J. C. (30), and J.H.F. (54). The normal ageing process may be expected to result in loss of skeletal calcium. The radiation doses received by the three subjects are shown in Table IV. These values were given by the Radiation Protection Service (Sutton) and are based on the counting of proton tracks in nuclear emulsions, using an R.B.E. value of 10 for neutrons of this energy. These values agree closely with those calculated direct from the neutron flux, and with those measured by an ionization chamber survey instrument.

TABLE IV.-Doses of Radiation Received by the Three Subjects

\begin{tabular}{c|c|cc} 
& \multicolumn{3}{c}{ Millirem } \\
\cline { 2 - 3 } Subject & Neutron & $\beta+\gamma$ & Total \\
\hline J.H.F. & 1,669 & 50 & 1,719 \\
M.J.C. & 1,321 & 50 & 1,371 \\
D.K.P. & 1,337 & 50 & 1,387
\end{tabular}

\section{Discussion}

There is strong clinical need for a sensitive measure of skeletal calcium. Radiographic techniques detect only relatively gross demineralization. Bone biopsies are valuable, but the interpretation of the histological picture is qualitative and often controversial. The biopsy samples, only a minute part of the total skeletal bone, may not be representative, and are not easily repeated. Chemical analysis of the biopsy is open to similar objections but presents the additional difficulty of expressing results in meaningful dimensions. The technique of estimation of bone mineral by gamma-ray absorption measurements (Cameron and Sorenson, 1963) may be helpful Unfortunately this and similar techniques, such as neutron activation of the leg (Kellershohn, 1968), necessarily sample a skeletal part unlikely to show best the changes in generalized skeletal diseases, such as osteoporosis. We have shown that neutron activation analysis may be used to provide a measure of total body calcium. The method is reproducible and should be more sensitive than currently used investigative techniques.

We have made no attempt to express the total body calcium derived from the ${ }^{49} \mathrm{Ca}$ activity in terms of grammes of calcium. An attempt to express the result in absolute terms would require construction of an elaborate phantom. Such a phantom would not take into account geometrical variation (and resulting variation of efficiency of activation and counting) between individuals. Provided the conditions of activation are carefully standardized the results expressed in terms of ${ }^{49} \mathrm{Ca}$ activity are equally meaningful. Though total body calcium and sodium vary independently, values for both are obtained from activation, so that the ${ }^{49} \mathrm{Ca} /{ }^{24} \mathrm{Na}$ ratio may be used to provide a measure of body calcium. We do not suggest that neutron activation analysis be used for single measurements in patients. The repeated determination of calcium in carefully selected patients should contribute significantly to the understanding of diseases of calcium metabolism and to their clinical management. There is need for sensitive techniques to assess therapeutic claims in a number of bone disorders. Bone disease is an important complication of repeated dialysis for chronic renal failure. By the time it can be diagnosed with current investigative methods, it is advanced. Activation analysis should result in earlier detection and treatment of such disease.

The most important practical consideration is safety. The radiation doses received by the three subjects have been carefully measured (Table IV). J.H.F., M. J. C., and D. K. P. received, respectively, total body doses of approximately 1,700 , 1,400 , and $1,400 \mathrm{mrem}$. These radiation doses are well within the permissible limit of 3,000 mrem per three calendar months for workers occupationally exposed to ionizing radiation. By comparison the Adrian Committee (1960) quote values of 740 mrem for a radiograph of the upper femur and 765 mrem for descending urography. An abdominal radiograph may deliver a dose of 100-200 mrem. These values refer to gonad doses. In the situations we envisage neutron activation analysis being clinically useful, repeated whole body activation would result in radiation doses that are safe, and frequently exceeded by currently accepted diagnostic techniques.

\section{Summary}

The feasibility of whole body neutron activation analysis, for the determination of total body calcium, has been explored by a series of experiments on inanimate phantoms, cadavers, and three living subjects. It has been shown that the method is safe, and that the results are reproducible. As well as being an important investigative tool, this technique should prove of great value in the diagnosis and management of metabolic bone diseases.

We are grateful for the help given by the following: Mr. R. F. Coleman (A.W.R.E., Aldermaston), Dr. John Rundo and his colleagues (A.E.R.E., Harwell), the staff of the Radiation Protection Service (Sutton), Dr. P. Dallas Ross (Department of Anatomy, University of Birmingham), Mr. J. Dealer, Mr. E. E. Cartwright, Mr. F. R. Stuart, Mr. A. Atafia, and Mr. R. Harris (Department of Physics, University of Birmingham).

The techniques described in this paper involving the neutron irradiation of living subjects have been approved by an ethical committee of Birmingham University. Clinicians and physicists 
were represented on the committee, which included the Radiation Protection Officers of the University and of the United Birmingham Hospitals. The work involving cadavers was done with the permission of the Inspector of Anatomy at the Home Office.

\section{REFERENCES}

Adrian Committee (1960). Radiological Hazards to Patients. Sccond report of the Committee. H.M.S.O., London.

Anderson, J., et al. (1964). Lancet, 21201.
Cameron, J. R., and Sorenson, J. (1963). Science, 142, 230.

Chamberlain, M. J., Fremlin, J. H., Peters, D. K., and Philip, Helen (1968a). Radioactive Isotopes in Clinical Medicine and Research. Report of VIII International Symposium. Urban and Schwarzenberg. To be published.

To be published.
Chamberlain, M. J., Fremlin, J. H., Peters, D. K., and Philip, Helen (1968b). Use of the Cyclotron for Whole Body Neutron Activation Analysis: Theoretical and Practical Considerations. To be published

Kellershohn, C. (1968). Radioactive Isotopes in Clinical Medicine and Research. Report of VIII International Symposium. Urban and Schwarzenberg. To be published.

Simon, G. (1965). Principles of Bone X-ray Diagnosis, 2nd ed. London.

\title{
Total Body Sodium by Whole Body Neutron Activation in the Living Subject: Further Evidence for Non-exchangeable Sodium Pool
}

\author{
M. J. CHAMBERLAIN,* M.B., M.R.C.P. ; J. H. FREMLIN, $\dagger$ M.A., D.SC., PH.D. \\ D. K. PETERS, $\ddagger$ M.B., M.R.C.P. ; HELEN PHILIP,§ PH.D.
}

Brit. med. F., 1968, 2, 583-585

The existence of a non-exchangeable sodium pool is suggested by the consistently low values for total exchangeable sodium measured by isotope dilution techniques (Edelman et al., 1954 ; Moore et al., 1963) compared with the values for total body sodium derived from chemical analysis of cadavers (Widdowson et al., 1951 ; Forbes and Lewis, 1956 ; Grove and Scott, 1957). The concept is supported by the failure of bone sodium to achieve the same specific activity as plasma sodium after injection of ${ }^{2 \cdot 2} \mathrm{Na}$ (Edelman et al., 1954). Anderson et al. (1964) found only a small difference between exchangeable sodium and whole body sodium determined by whole body neutron activation in two living subjects. These workers suggested that this difference corresponded to the fraction $(<0.5 \%)$ with a long biological half-life in ${ }^{22} \mathrm{Na}$ turnover studies (Miller et al., 1957 ; Richmond, 1958).

We have carried out whole body neutron activation in three normal male subjects and have found a consistent and substantial difference (approximately 17\%) between activatable and exchangeable sodium. Our values for activatable sodium are considerably lower than those for whole body sodium based on chemical analysis of cadavers.

\section{Methods}

These studies were made as part of a programme in which measurements of whole body calcium were also made (Chamberlain et al., 1968c). The conditions of activation of the human subjects, with the use of a cyclotron as neutron source, and the whole body counter have been described previously (Chamberlain et al., 1968a, 1968b).

A 68-kg. polyethylene phantom "standard man" containing $74.9 \mathrm{~g}$. of sodium as sodium chloride dissolved in 57 litres of water was separately activated under comparable conditions except that the irradiation time was increased to 30 minutes to facilitate counting and the irradiation was carried out from one direction only. As in the human studies a wooden coffin $1.5 \mathrm{~cm}$. thick was used to provide moderation of fast neutrons. The activities produced in suitably placed indium foils were taken as a measure of neutron flux.

* Lecturer in Experimental Pathology, University of Birmingham.

+ Professor of Applied Radioactivity, University of Birmingham.

† Honorary Research Fellow in Experimental Pathology, University of Birmingham. Present address: Division of Biophysics, National Institute of Medical Research, London S.W.7.

$\checkmark$ Research Associate in Medical Biochemistry, University of Birmingham.

C
${ }^{24} \mathrm{Na}$ produced from ${ }^{23} \mathrm{Na}$ by neutron capture has a half-life of 15 hours and two gamma emissions of 1.38 and $2.76 \mathrm{MeV}$. Sodium activities in this study are based on measurement of the higher peak in the energy band 2.58-2.92 MeV. Counting for sodium was started approximately three hours after activation, when the short-lived isotopes also produced during activation had decayed away. Counts were repeated three times in the first 30 hours, and the initial ${ }^{24} \mathrm{Na}$ activity was found by extrapolation to time zero. The activity in the energy band counted was shown to have the half-life of ${ }^{24} \mathrm{Na}$. The counting efficiency of the whole body counter for ${ }^{24} \mathrm{Na}$ was measured in the phantom and in each of the three subjects after injection of $2 \mu \mathrm{Ci}$ of ${ }^{24} \mathrm{Na}$ on a separate occasion. The 24 -hour exchangeable sodium was measured a few days later by conventional isotope dilution techniques (Veall and Vetter, 1958) using $20 \mu \mathrm{Ci}$ of ${ }^{24} \mathrm{Na}$.

\section{Results}

The physical characteristics of the three subjects are shown in Table I. It will be seen that J.H.F. and D.K.P. are very similar in weight and build but differ in age, whereas M.J.C. and D.K.P. are very similar in age. The ${ }^{24} \mathrm{Na}$ activities produced in each of the subjects and the phantom are seen in Table II. The corresponding ${ }^{116} \mathrm{In}$ counts are a measure of the neutron flux and so of neutron dose received by each subject.

Total body sodium was calculated from the formula:

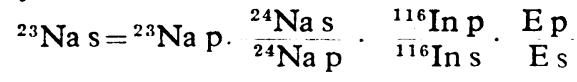

Where: the suffix s denotes the subject.

the suffix $\mathrm{p}$ denotes the phantom.

${ }^{23} \mathrm{Na}$ denotes stable sodium.

${ }^{24} \mathrm{Na}$ the radio sodium activity induced.

${ }^{116}$ In the indium activity induced (neutron dose).

$\mathrm{E}$ the efficiency of counting ${ }^{24} \mathrm{Na}$.

Table III gives the values for total body sodium after correction for differences in irradiation and counting efficiency, and contrasts them with the 24-hour exchangeable sodium for each of the three subjects. 